\title{
Which Lower Limb Frontal Plane Sensory and Motor Functions Predict Gait Speed and Efficiency on Uneven Surfaces in Older Persons With Diabetic Neuropathy?
}

\author{
Lara Allet, PT, PhD, Hogene Kim, MS, PhD, James A. Ashton-Miller, PhD, \\ James K. Richardson, MD
}

Objective: To identify which frontal plane lower limb sensorimotor functions predict gait speed and efficiency (step-width-to-step-length ratio) on an uneven surface.

Design: Cross-sectional observational study.

Setting: A biomechanics research laboratory.

Participants: Thirty-three subjects (14 women [42.4\%]; 21 with diabetic distal symmetric peripheral neuropathy $[63.6 \%]$ ), with a spectrum of lower limb sensorimotor functions that ranged from normal to marked diabetic neuropathy.

Methods: Independent variables included ankle inversion-eversion proprioceptive thresholds, and normalized measures of maximum voluntary strength and maximum rate of torque development (RTD) of hip abduction-adduction and ankle inversion-eversion. Kinematic data were obtained by using an optoelectronic system as subjects walked over an uneven 10-m surface.

Main Outcome Measures: Dependent variables included gait speed and efficiency (determined by step-width-to-step-length ratio) on an uneven surface.

Results: Hip adduction RTD and ankle inversion RTD predicted 54\% of gait speed, with the former predicting the majority (44\%). Ankle inversion RTD was the only significant predictor of gait efficiency, which accounted for $46 \%$ of its variability. Age did not predict gait speed or efficiency.

Conclusions: The rapid generation of strength in the frontal plane at the hip and ankle is responsible for the successful negotiation of irregular surfaces in older persons. Age demonstrated no independent influence. Training regimens in older persons should include maneuvers that rapidly develop strength in hip adductors and ankle invertors if navigation of uneven surfaces is a functional goal.

PM R 2012;4:726-733

\section{INTRODUCTION}

The prevalence of type 2 diabetes mellitus is increasing worldwide [1]. Therefore, it is anticipated that the prevalence of one of its common complications, a distal symmetric peripheral neuropathy (DSPN), will increase as well. It is broadly recognized that DSPN leads to a decrement in distal lower limb sensory function; however, there also is a neuropathy-related decrease in distal motor function, even among those with relatively mild disease [2]. The degradation in lower limb sensorimotor function often results in balance and gait impairment among older persons with diabetic DSPN [3-7]. These gait abnormalities are accentuated when persons with DSPN walk on uneven surfaces [3,5]. Accordingly, the majority of falls in older persons with neuropathy occur when these individuals are walking on an irregular surface [5]. Despite this link between walking surface irregularity and falls, the great majority of gait research is performed on smooth surfaces [4], and so the lower limb sensorimotor features that allow safe and effective gait on irregular surfaces have not been determined. The question is of clinical relevance, given that exercise, often in the form of walking, is fundamental to the management of type 2 diabetes mellitus [8].

L.A. University of Applied Sciences of Western Switzerland, Geneva, Switzerland Disclosure: $8, \mathrm{NIH}$

H.K. Department of Mechanical Engineering, University of Michigan, Ann Arbor, Ml Disclosure: nothing to disclose

J.A.A.-M. Department of Mechanical Engineering, University of Michigan, Ann Arbor, Ml Disclosure: nothing to disclose

J.K.R. Department of Physical Medicine and Rehabilitation, University of Michigan, 325 East Eisenhower Pkwy, Ann Arbor, Ml 48108 Address correspondence to: J.K.R.; e-mail: jkrich@umich.edu

Disclosure: 8, NIH

Disclosure Key can be found on the Table of Contents and at www.pmrjournal.org

Research support: This work was supported by the National Institutes of Health (ROI AG026569), PHS grants (P3OAG024824), and the Swiss National Foundation (IZKOZ3 133925)

The peer reviewers and all others who control content have no relevant financial relationships to disclose.

Submitted for publication February 7, 2012 accepted May 8, 2012 
There is increasing recognition of the importance of lateral (or frontal plane) control during ambulation. In addition to the markedly increased injury potential associated with lateral falls [9], there is a growing appreciation of the importance of frontal plane sensory and motor function with respect to 1-legged balance, fall risk, and fall prevention [10-13]. However, the relative importance of lower limb sensory and motor functions involved in lateral control with respect to functional gait, as defined by speed and efficiency, on an uneven surface has not been explored. Speed and efficiency of gait are relevant measures, given that a slower gait speed is associated with increased fall risk [14], increased morbidity and mortality [15], reduced overall health status, and increased duration of hospital stay [16], and that an efficient gait allows greater ease in daily activities that involve accessing the community. In studies that identified optimal gait efficiency in humans by measuring mechanical work as well as metabolic costs, the latter by means of open circuit respirometry, the optimal step-width-to-step-length ratio is 0.14 [17-19], with greater ratios leading to greater energy costs.

Therefore, the objective of this research was to identify the lower limb sensory and/or motor functions involved in frontal plane control that most powerfully influence gait speed and efficiency on an uneven surface in older persons. To achieve this objective, ankle and hip motor functions, and ankle sensory function relevant to frontal plane control were measured in a group of older persons with a spectrum of peripheral neurologic functions that ranged from normal to moderate-severe diabetic DSPN. Subsequent determination of gait speed and efficiency on an uneven surface allowed the exploration of relationships between lower limb sensorimotor functions and these gait characteristics. It was hypothesized that greater hip and ankle motor function, and more precise ankle sensory function, would be associated with increased gait speed and efficiency on the irregular surface.

\section{METHODS}

\section{Subjects}

Subjects were recruited from the University of Michigan Orthotics and Prosthetics Clinic, Endocrinology Clinic, and the Older Americans Independence Center Human Subjects Core. The research protocol was approved by the University of Michigan Institutional Review Board, and all subjects provided written informed consent. Inclusion criteria included the following: age between 50 and 85 years, mass not greater than $136 \mathrm{~kg}$ (so as to not exceed the suspension harness safety margin), a history of type 2 diabetes mellitus for subjects with DSPN, the ability to walk household distances without assistance or assistive devices, and dorsiflexion ankle strength at least against gravity (grade $\geq 3$ by manual muscle testing). The history of type 2 diabetes mellitus was confirmed by medical record review of elevated fasting glucose $(>125 \mathrm{mg} / \mathrm{dL})$ and the ongoing use of oral hypoglycemic agents or insulin. The presence of DSPN was confirmed by (a) symptoms consistent with neuropathy (the subject reported altered sensation in the distal lower limbs; (b) signs consistent with neuropathy (Michigan Diabetes Neuropathy Score [MDNS]) $\geq 10$ [20]; (c) electrodiagnostic evidence of neuropathy (bilaterally abnormal peroneal motor responses recording over the extensor digitorum brevis, defined as amplitude of $<2 \mathrm{mV}$ and/or latency of $>6.2 \mathrm{~ms}$ and/or conduction velocity of $<41.0 \mathrm{~m} / \mathrm{s}$ ). The MDNS assigns a numerical score to clinical measures of distal strength, sensation, and reflexes, which then summed to provide the MDNS score, with a greater score suggesting more severe neuropathy. The MDNS score has been found to strongly correlate with more detailed neuropathy severity measuring systems [20]. The subjects without DSPN had no history of diabetes mellitus, no symptoms or signs of DSPN (MDNS < 10), and normal peroneal nerve conduction studies. The subjects with or without DSPN were excluded if they reported a fall within 1 month of testing or if they had a history or clinically evident central nervous system dysfunction (eg, hemiparesis, myelopathy, cerebellar ataxia). Additional exclusion criteria included the following: neuromuscular disorders other than DSPN (eg, myopathy or neuromuscular junction disorders), evidence of vestibular dysfunction, a history of angina or angina-equivalent symptoms with exercise, plantar skin sore or joint replacement within the previous year, symptomatic postural hypotension, significant musculoskeletal deformity (eg, amputation or Charcot changes), lower limb or spinal pain that limited standing to less than 10 minutes, or walking less than 1 block.

\section{Evaluation of Lower Limb Sensorimotor Function}

Ankle Sensory Function. Ankle proprioception thresholds were determined as previously described [21]. In brief, the subjects stood with the foot and ankle being tested in a $40 \times 25-\mathrm{cm}$ cradle that rotated in the frontal plane (inversion and eversion) (Figure 1). The cradle was rotated by a servomotor equipped with an 8000 line rotary encoder (Aerotech 1000 servomotor; Aerotech, Inc, Pittsburgh, PA). The subject responded to the direction of the rotation with a hand-held joystick. Four blocks of 25 trials (randomly, 10 eversion, 10 inversion, and 5 dummy trials) were presented. Each block was interspersed with 2 - to 5 -minute rest intervals. The ankle proprioception threshold was defined as the smallest rotational displacement of the ankle that a subject could detect with 100\% accuracy.

Ankle Motor Function. During maximum voluntary strength testing, the subjects stood on a force plate (Model OR6-7 Force Plate; AMTI Inc, Watertown, MA) and touched hand rails on both sides as needed (Figure 2). The subjects then lifted $1 \mathrm{leg}$, shifted their center of gravity as far laterally 


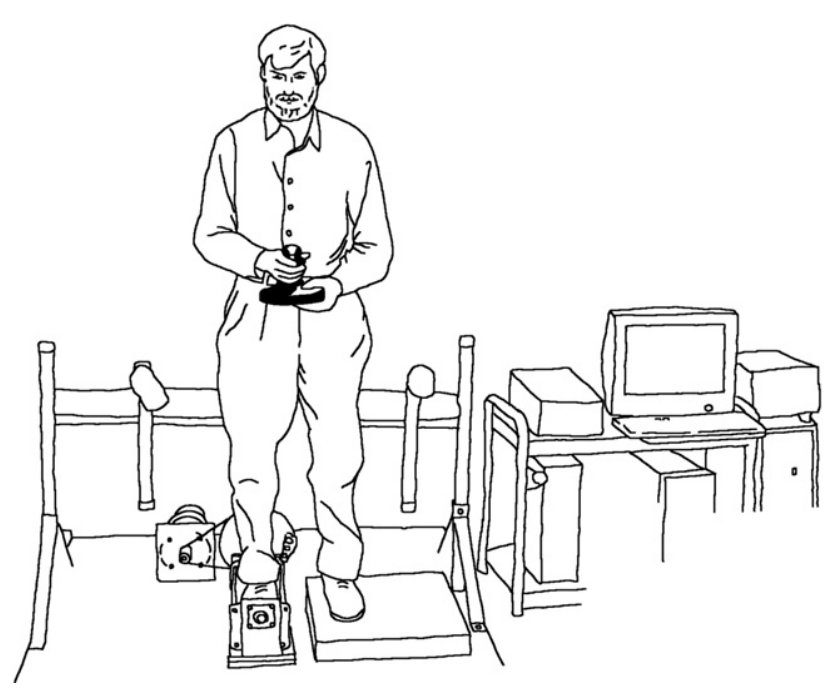

Figure 1. Apparatus for determining frontal plane ankle proprioceptive thresholds.

under their foot as possible and lifted their hands from the rails for 3 seconds. The test was repeated 3 times for the lateral margin of the foot (maximum voluntary inversion) and repeated for the medial margin of the foot (maximum voluntary eversion). To measure ankle rate of torque development (RTD), the subjects stood on the test foot on the force plate and moved the center of ground support reaction from the lateral margin of the foot to the medial margin as quickly as possible and then back again to the lateral margin, as previously described [2]. Three trials, each trial with 5 medial-lateral movements, were performed. The subjects were allowed to touch horizontal hand rails as needed.

Hip Motor Function. A custom, whole-body dynamometer (BioLogic Engineering Inc, Dexter, MI) was used to measure maximum voluntary strength and RTD of frontal plane hip musculature [22]. The subject lay supine on a horizontal bench with the pelvis and upper body immobilized with adjustable harness straps, and the limb being tested was secured with straps against a lever, which allowed all measurements to be made in a gravity-free plane (Figure 3). During maximum voluntary strength tests, the subjects progressively increased their isometric effort to their maximum over a count of 3 seconds, held it for 2 seconds, and relaxed. To quantify the rate of isometric strength development, the subjects increased their effort as rapidly as possible for 3 seconds. Three trials were performed with 1-minute rests between trials. The subjects had a real-time visual display of the force generated to allow them to evaluate their efforts. Ankle and hip motor functions were normalized for body size, defined as body height multiplied by weight in units of Newton-m.

\section{Gait Analyses}

Gait analyses were performed as previously described [6]. All subjects wore flat-soled athletic shoes (New Balance Athletic Shoe Inc, Boston, MA) as well as a full-body safety harness, which was adjusted so that their knees or other body parts could not touch the floor in the event of a fall. The subjects walked on a $1.5 \times 10-\mathrm{m}$ irregular surface that was created by randomly fixing triangular wooden prisms under a strip of industrial carpeting (Figure 4). The position of the prisms was not changed between trials or subjects. Each subject walked across the surface 10 times: 2 accommodation trials and 8 data acquisition trials. Before each trial, the subjects were instructed, "Please walk at a comfortable pace, as if you were walking to the corner to mail a letter." Optoelectronic markers were placed on the patient over the midline of the trunk at the umbilicus and on the base and top of aluminum tabs that were inserted into the laces of the shoes in midline and flexed to vertical. Step width and step length were defined as the medial-lateral and anterior-posterior distance, respectively, between foot markers during double support. An optoelectronic camera system measured kinematic data at 100 Hz (Optotrak 3020; Northern Digital Corp, Waterloo,

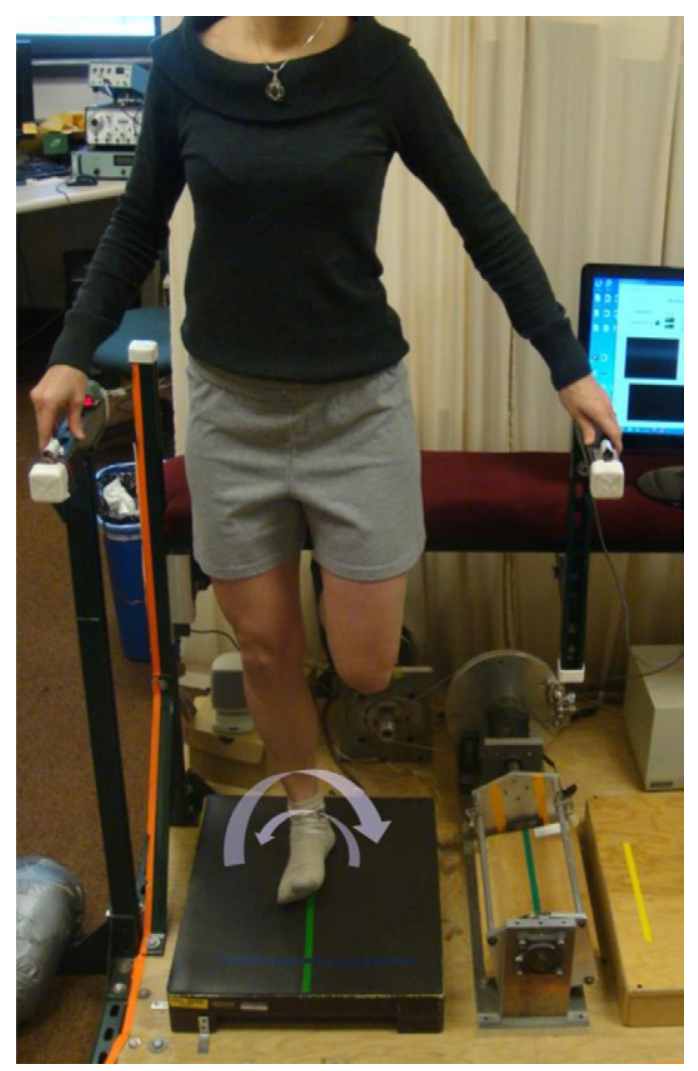

Figure 2. Subject standing on a force plate inverting and everting the ankle as quickly as possible and as far as possible so as to determine ankle rate of torque generation and maximum voluntary strength, respectively. 


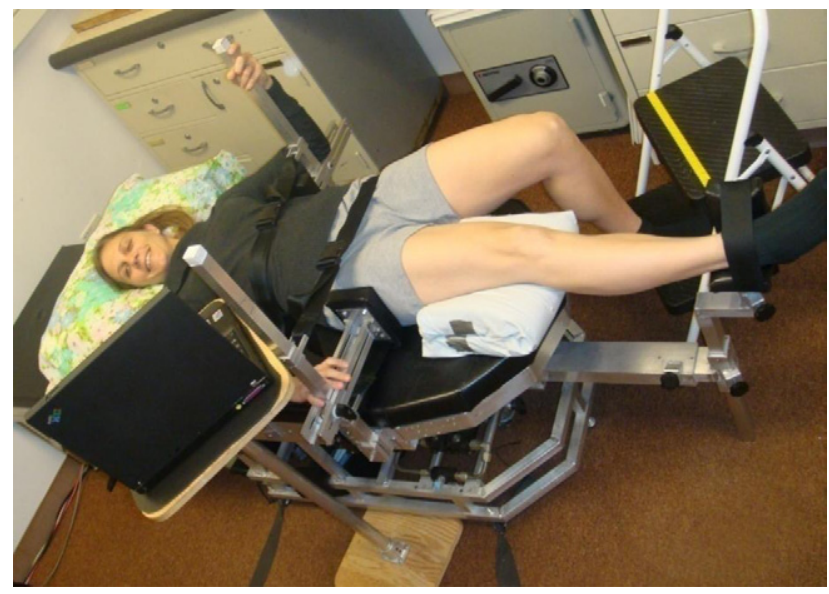

Figure 3. Whole-body dynamometer used to measure maximum voluntary strength and rate of torque development of frontal plane hip musculature.

ON, Canada) [6]. These data were then processed by using a custom MATLAB 1 algorithm to quantify walking speed, step width, and step length, as previously described [6].

\section{Statistical Analyses}

Descriptive statistics were determined for all measures. Data were examined for normality and screened for outliers. Pearson product correlation coefficients were calculated to assess relationships between lower limb sensorimotor functions, gait speed, and step-width-to-step-length ratio. Multiple regression models were used to determine the independence and relative influence of sensorimotor functions (independent variables) and gait speed and step-width-to-step-length ratio (dependent variables). Sensorimotor functions with significant relationships to gait speed or efficiency were introduced in a stepwise regression model as potential predictors by using age and body mass index as covariates. The significance level for all tests was set at .05. Statistical analyses used SPSS for Windows (Rel.11.0.1.2001; SPSS Inc, Chicago, IL).

\section{RESULTS}

\section{Subjects}

Thirty-three subjects were enrolled (14 women [42.4\%]; 1 with diabetic DSPN [63.6\%]). Means and standard deviations of age, body mass index, and MDNS results are presented in Table 1.

\section{Univariate Analyses}

Correlation coefficients between lower limb sensorimotor functions and gait speed, as well as gait efficiency, are listed in Tables 2 and 3. Analysis of the data indicates that all of the sensorimotor functions were significantly associated with gait speed with correlations ( $r$ ) that ranged from 0.412 to 0.665. In addition, all sensorimotor functions except ankle eversion RTD were significantly associated with gait efficiency, with significant correlations that ranged from 0.385 to 0.648 . Age was indirectly related to speed and efficiency $(\mathrm{r}=-0.447 ; \mathrm{P}=.009$; and $\mathrm{r}=0.425 ; \mathrm{P}=.014$, respectively), whereas body mass index correlated with neither gait speed nor efficiency.

\section{Multivariate Analyses}

Regression analyses identified 2 significant predictors of gait speed on the irregular surface (Table 4). Hip adductor RTD and ankle inversion RTD predicted more than $50 \%$ of the variance in gait speed, with hip adductor RTD accounting for more than $40 \%$. The only significant predictor of gait effi-
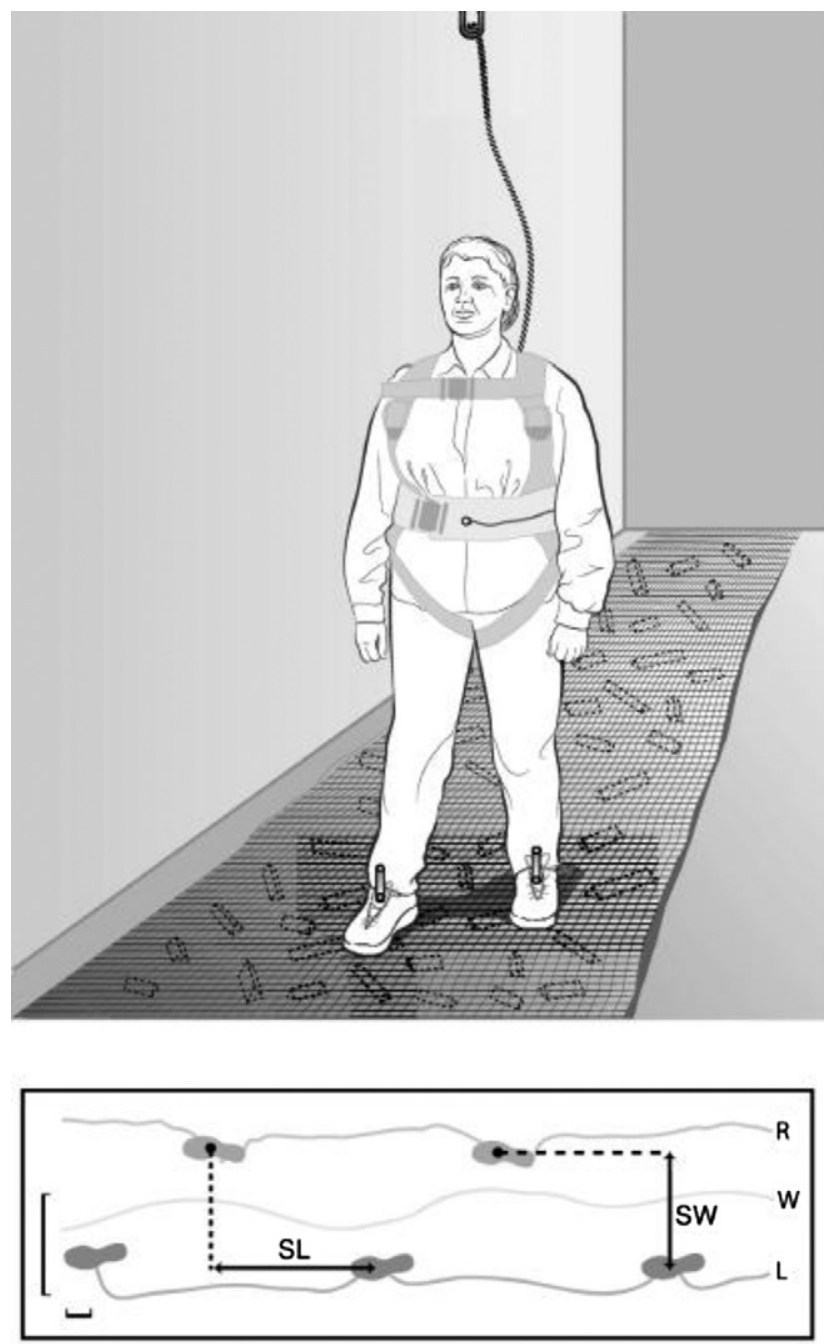

Figure 4. Experimental setup for determining gait speed and step-width-to-step length ratio on an irregular surface. 
Table 1. Subject information

\begin{tabular}{lccc}
\hline Parameter $(\mathbf{N}=\mathbf{3 3})$ & Minimum & Maximum & Mean \pm SD \\
\hline Age, $y$ & 52.0 & 85.0 & $69.67 \pm 8.89$ \\
Height, $\mathrm{cm}$ & 150.0 & 188.0 & $171.72 \pm 10.09$ \\
Weight, $\mathrm{kg}_{\mathrm{BMl}, \mathrm{m}^{2} / \mathrm{kg}}$ & 49.5 & 125.0 & $88.74 \pm 19.04$ \\
MDNS (0-46) & 19.2 & 46.5 & $30.11 \pm 6.30$ \\
& 0.0 & 31.0 & $9.5 \pm 8.4$
\end{tabular}

$\mathrm{SD}=$ standard deviation; $\mathrm{BMI}=$ body mass index; MDNS = Michigan Diabetes Neuropathy Score.

ciency (step-width-to-step-length ratio) was ankle inversion RTD, which accounted for $46 \%$ of the variance (Table 5).

\section{DISCUSSION}

The most important finding was that frontal plane motor function at the hip and ankle (adduction and inversion, respectively) explained nearly three-fourths of the variance in gait speed and nearly half of the variance in gait efficiency among older subjects with varying degrees of peripheral neurologic function when walking on an irregular surface. Moreover, it was the RTD of these muscles, rather than their maximal strength, that was critical to gait speed and efficiency under the experimental conditions. In contrast, ankle proprioceptive function did not appear to influence gait when frontal plane motor function and confidence were taken into account. Finally, age did not independently predict gait speed or efficiency on the irregular surface.

Although the importance of frontal plane motor function relative to that more routinely studied in the sagittal plane (ie, knee extensors and plantar flexors) was not determined, comparisons with other work are useful. For example, in prior work, we found that frontal plane hip strength explained about $45 \%$ of unipedal balance time [22], whereas a separate study found that knee extensor and flexor strength explained only $10 \%$ [23]. Similarly, in a study of older adults with diabetic DSPN, sagittal plane muscle strength predicted about a fifth of gait speed change when subjects transitioned from smooth to uneven terrain [24], substantially less than in our study, in which frontal plane motor function predicted more than half of the variance in gait speed. These comparisons suggest that motor function in the frontal plane, rather than that in the more frequently studied sagittal plane, exerts the dominant influence when balance is challenged. However, we did not study sagittal plane sensorimotor functions, and, therefore, the relative importance of the sagittal plane sensorimotor functions to frontal plane sensorimotor function with regard to standard or perturbed gait is not known; this represents a limitation of this research.

Rates of torque generation at the hip and ankle were more important than the maximum strengths of these same muscle groups, a point supported by other research that emphasizes motor response speed for successful recovery from a perturbation. Jumping distance [25] and gluteus medius onset latency [10] in response to a perturbation were the best predictors of prospectively identified falls among community-dwelling older persons. Similarly, jump height was the best clinical measure of ability to recover from an induced trip [26], and individuals routinely recovered from trip durations of less than $700 \mathrm{~ms}$ but could not recover from longer trip durations [27]. Our results add to the current research and suggest that successful response to a balance challenge, including gait on an irregular surface, is time dependent and so requires short response latencies and rapid generation of force. Similarly, improvement in lower limb power led to increased gait speed in mobility impaired older adults independent of lower limb strength [28]. The greater importance of hip adduction and ankle inversion RTD, rather than abduction and eversion, is likely related to the ability of the former movements to generate a laterally directed ground reaction force that allows control of a laterally displaced center of mass [29].

The absence of a significant, independent age effect implies that aging does not intrinsically contribute to difficulty navigating an irregular surface. It is likely that age is a marker for decrements in RTD in frontal plane muscles, along with reductions in plantar flexor power [30], which are the true sources of apparent age-related gait change. Although a larger number of subjects might reveal an independent age effect, analysis of our data suggests that such an effect would be minor in comparison with lower limb motor function.

The apparent lack of influence of frontal plane proprioceptive sensory function at the ankle was not anticipated, given its importance to unipedal stance time [21,22]. How-

Table 2. Relationships between sensory and motor functions and gait speed

\begin{tabular}{|c|c|c|c|c|}
\hline Variable & $\mathbf{N}$ & Correlation Coefficient & $95 \% \mathrm{Cl}$ & $P$ Value \\
\hline Ankle inversion rate of torque development & 32 & 0.665 & $0.490-0.802$ & $<.001$ \\
\hline Hip add rate of torque development & 33 & 0.626 & $0.422-0.796$ & $<.001$ \\
\hline Hip abd rate of torque development & 33 & 0.504 & $0.198-0.721$ & .003 \\
\hline Hip add maximum voluntary strength & 33 & 0.475 & $0.115-0.718$ & .005 \\
\hline Ankle inversion maximum voluntary strength & 29 & 0.491 & $0.263-0.692$ & .007 \\
\hline Ankle eversion maximum voluntary strength & 31 & 0.447 & $0.032-0.716$ & .012 \\
\hline Ankle eversion rate of torque development & 31 & 0.441 & $0.196-0.689$ & .013 \\
\hline Hip abd maximum voluntary strength & 33 & 0.422 & $0.082-0.699$ & .015 \\
\hline Ankle proprioceptive threshold & 33 & -0.412 & -0.639 to -0.092 & .017 \\
\hline
\end{tabular}

$\mathrm{Cl}=$ confidence interval; abd = abductor; add = adductor. 
Table 3. Relationships between sensory and motor functions and step-width-to-step-length ratio

\begin{tabular}{|c|c|c|c|c|}
\hline Variable & $\mathbf{n}$ & Correlation Coefficient & $95 \% \mathrm{Cl}$ & $P$ Value \\
\hline Hip add maximum voluntary strength & 33 & -0.648 & -0.802 to -0.425 & $<.001$ \\
\hline Ankle inversion rate of torque development & 31 & -0.636 & -0.783 to -0.414 & $<.001$ \\
\hline Ankle proprioceptive threshold & 33 & 0.503 & 0.261 to 0.705 & .003 \\
\hline Ankle eversion rate of torque development & 31 & -0.514 & -0.690 to -0.312 & .003 \\
\hline Hip abd rate of torque development & 33 & -0.486 & -0.722 to -0.183 & .004 \\
\hline Hip abd maximum voluntary strength & 33 & -0.475 & -0.699 to -0.137 & .005 \\
\hline Hip add rate of torque development & 33 & -0.471 & -0.695 to -0.161 & .006 \\
\hline Ankle inversion maximum voluntary strength & 29 & -0.385 & -0.614 to -0.102 & .039 \\
\hline Ankle eversion maximum voluntary strength & 31 & -0.326 & -0.567 to -0.002 & .074 \\
\hline
\end{tabular}

$\mathrm{Cl}=$ confidence interval; $\mathrm{abd}=$ abductor; add $=$ adductor .

ever, this finding is consistent with other analyses of these same subjects, which found that hip motor function compensates for imprecise ankle proprioception during 1-legged balance [22]. The apparent lack of ankle sensory contribution may also be related to subjects seeing the walking surface irregularities, which could have allowed visual compensation for somatosensory deficits. In support, lower field visual information is important to adapting to varying walking surfaces [31] and so proprioceptive thresholds might have played a measurable role if lower field vision was occluded.

The study has strengths in comparison with prior work. Among these is the simultaneous quantification of sensory and motor function relevant to frontal plane control within each subject, a novel feature of the study. In addition, the subjects were selected to represent a spectrum of peripheral sensorimotor function, and the presence and severity of DSPN were determined by history, physical examination, and nerve conduction studies, as has been recommended [32]. In contrast, studies often use a single modality, such as vibratory perception threshold or monofilament testing to determine the presence and severity of neuropathy. The measurement of RTD is infrequently determined but is an advantage, given other work that found that diabetic neuropathy is associated with selective dropout of type II motor neurons and reduced rate of force generation $[33,34]$. The use of an uneven walking surface is more functionally relevant than gait analysis on a smooth surface, as is typically used, particularly given the fall risk associated with irregular surfaces [5].

One of the study's potential limitations is the combining of subjects who had diabetic DSPN with subjects who had neither diabetes nor neuropathy. This study population was chosen so that it would include a broad spectrum of peripheral neurologic functions. The subjects with diabetes but without neuropathy would be less likely to represent optimal peripheral neurologic function. In addition, this concern is mitigated by evidence that declining peripheral neurologic function, rather than the presence of diabetes mellitus, is primarily responsible for impairments in ankle motor function, balance, and age-associated mobility loss [2,35-37]. Another limitation involves the method for determining ankle motor function that assumed the ankle center of rotation to be mid way between the malleoli. However, this technique has been used previously, and its validity is supported by the relationship between ankle strength determined in this manner and the presence of neuropathy and unipedal stance time [2]. The method for determining hip strength applied a varus-valgus stress on the knee. Although no subjects reported pain, they may have not given maximal effort for fear of causing discomfort. In addition, it has recently been demonstrated that the knee has frontal plane proprioceptive function [38], something for which we did not account. The loss of data due to technical difficulties may have altered the study outcome. For example, the correlation of hip adduction MVS with step-width-to-steplength ratio was stronger than that of ankle inversion RTD when 33 subjects were considered. However, in the regression only 29 subjects were available with all data and the latter became the significant predictor.

The results of this research have potential clinical application. Specifically, it appears that strengthening regimens in older persons with diabetic DSPN should focus on the capacity to develop strength quickly, rather than on maximal strength generated gradually. In addition, training should involve muscles of frontal plane control rather than focusing exclusively on muscles involved in sagittal plane control; however, this is not routinely recommended $[39,40]$. The dominant effect of the proximally located hip muscles on gait speed on an uneven surface suggests that even patients with more severe PN can benefit from training, given the distal nature of neuropathic disease. It is less clear that patients

Table 4. Sensory and motor functions predicting gait speed on the irregular surface

\begin{tabular}{|c|c|c|c|c|c|c|c|}
\hline Parameters $(\mathrm{N}=29)$ & $\boldsymbol{R}$ & $R^{2}$ & Adjusted $R^{2}$ & SE Estimate & $R^{2}$ Change & F Change & Sig. F Change \\
\hline Hip add RTD & 0.661 & 0.436 & 0.416 & 0.129 & 0.436 & 20.907 & 0.000 \\
\hline Ankle inv RTD & 0.735 & 0.540 & 0.504 & 0.119 & 0.103 & 5.826 & 0.023 \\
\hline
\end{tabular}

SE = standard error; Sig = significance; Hip add RTD = rate of torque development of hip adductors; Ankle Inv RTD = rate of torque development of ankle inversion. 
Table 5. Sensory and motor functions predicting step-width-to-step-length ratio

\begin{tabular}{lccccccc}
\hline Parameter $(\mathbf{N}=\mathbf{2 9})$ & $\boldsymbol{R}$ & $\boldsymbol{R}^{\mathbf{2}}$ & Adjusted $\boldsymbol{R}^{\mathbf{2}}$ & SE Estimate & $\boldsymbol{R}^{\mathbf{2}}$ Change & F Change & Sig. F Change \\
\hline Ankle Inv RTD & 0.678 & 0.460 & 0.440 & 0.061 & 0.460 & 22.960 & 0.000 \\
\hline
\end{tabular}

$\mathrm{SE}=$ standard error; $\mathrm{Sig}=$ significance; Ankle Inv RTD = rate of torque development of ankle inversion

with PN, particularly those with more severe impairments, can increase the ankle inversion rate of torque generation. However, some strengthening is likely possible in most cases, given that both the anterior and posterior tibialis muscles perform this function, with the latter muscle innervated by the tibial nerve, which takes a shorter route to its target, which renders it relatively less affected in a length-dependent neuropathic process. In support, improvements in tandem stance, unipedal stance, and functional reach were noted in older subjects with diabetic DSPN who underwent a 3-week regimen of ankle strengthening [41].

\section{CONCLUSION}

Analysis of our results suggests that a future trial that examines the effect of a training program designed to increase the rate of torque generation in frontal plane muscles in older persons with diabetic PN is reasonable, using gait speed and the ability to tolerate perturbations while walking as outcomes. It is tempting to suggest that increasing the frontal plane rate of torque generation will reduce fall risk in older patients with diabetic PN when walking on an uneven surface. Although this may be true, that specific hypothesis was not explored, and is a question that merits further study. The absence of influence of ankle proprioceptive function is surprising but may, as suggested above, show influence if the lower visual field is obscured. Such a study has special relevance to the diabetic population, given the likelihood that some patients will have visual impairment from retinopathy.

\section{REFERENCES}

1. Wild S, Roglic G, Green A, Sicree R, King H. Global prevalence of diabetes: Estimates for the year 2000 and projections for 2030. Diabetes Care 2004:27:1047-1053

2. Gutierrez EM, Helber MD, Dealva D, Ashton-Miller JA, Richardson JK. Mild diabetic neuropathy affects ankle motor function. Clin Biomech (Bristol, Avon) 2001;16:522-528.

3. Allet $\mathrm{L}$, Armand $\mathrm{S}$, de Bie RA, et al. Gait alterations of diabetic patients while walking on different surfaces. Gait Posture 2009;29:488-493.

4. Allet L, Armand S, Golay A, Monnin D, de Bie RA, de Bruin ED. Gait characteristics of diabetic patients: A systematic review. Diabetes Metab Res Rev 2008;24:173-191.

5. DeMott TK, Richardson JK, Thies SB, Ashton-Miller JA. Falls and gait characteristics among older persons with peripheral neuropathy. Am J Phys Med Rehabil 2007;86:125-132.

6. Richardson JK, Thies SB, DeMott TK, Ashton-Miller JA. A comparison of gait characteristics between older women with and without peripheral neuropathy in standard and challenging environments. J Am Geriatr Soc 2004:52:1532-1537.
7. Richardson JK, Ashton-Miller JA, Lee SG, Jacobs K. Moderate peripheral neuropathy impairs weight transfer and unipedal balance in the elderly. Arch Phys Med Rehabil 1996;77:1152-1156.

8. Matheson GO, Klugl M, Dvorak J, et al. Responsibility of sport and exercise medicine in preventing and managing chronic disease: Applying our knowledge and skill is overdue. Br J Sports Med 2011;45:12721282.

9. Greenspan SL, Myers ER, Kiel DP, Parker RA, Hayes WC, Resnick NM Fall direction, bone mineral density, and function: Risk factors for hip fracture in frail nursing home elderly. Am J Med 1998;104:539-545.

10. Brauer SG, Burns YR, Galley P. A prospective study of laboratory and clinical measures of postural stability to predict community-dwelling fallers. J Gerontol A Biol Sci Med Sci 2000;55:M469-M476.

11. Hilliard MJ, Martinez KM, Janssen I, et al. Lateral balance factors predict future falls in community-living older adults. Arch Phys Med Rehabil 2008:89:1708-1713.

12. Liu J, Lockhart TE. Age-related joint moment characteristics during normal gait and successful reactive-recovery from unexpected slip perturbations. Gait Posture 2009;30:276-281.

13. Rogers MW, Mille ML. Lateral stability and falls in older people. Exerc Sport Sci Rev 2003;31:182-187

14. Espy DD, Yang F, Bhatt T, Pai YC. Independent influence of gait speed and step length on stability and fall risk. Gait Posture 2010;32:378382.

15. Afilalo J, Eisenberg M, Morin J, et al. Gait speed as an incremental predictor of mortality and major morbidity in elderly patients undergoing cardiac surgery. J Am Coll Cardiol 2010;56:1668-1676.

16. Purser JL, Weinberger $M$, Cohen HJ, et al. Walking speed predicts health status and hospital costs for frail elderly male veterans. J Rehabil Res Dev 2005;42:535-546

17. Kuo $\mathrm{AD}$. A simple model of bipedal walking predicts the preferred speed-step length relationship. J Biomech Eng 2001;123:264-269.

18. Kuo AD. Energetics of actively powered locomotion using the simplest walking model. J Biomech Eng 2002;124:113-120.

19. Donelan JM, Kram R, Kuo AD. Mechanical and metabolic determinants of the preferred step width in human walking. Proc Biol Sci 2001;268: 1985-1992

20. Feldman EL, Stevens MJ, Thomas PK, Brown MB, Canal N, Greene DA. A practical two-step quantitative clinical and electrophysiological assessment for the diagnosis and staging of diabetic neuropathy. Diabetes Care 1994;17:1281-1289

21. Son J, Ashton-Miller JA, Richardson JK. Do ankle orthoses improve ankle proprioceptive thresholds or unipedal balance in older persons with peripheral neuropathy? Am J Phys Med Rehabil 2010;89:369-375.

22. Allet LK, H; Ashton-Miller, J; DeMott T; Richardson JK. Frontal plane hip and ankle sensorimotor function, not age, predicts unipedal stance time. Muscle Nerve 2011. In press.

23. Citaker S, Kaya D, Yuksel I, et al. Static balance in patients with patellofemoral pain syndrome. Sports Health 2011;3:524-527.

24. Allet $\mathrm{L}$, Armand $\mathrm{S}$, de Bie RA, et al. Clinical factors associated with gait alterations in diabetic patients. Diabet Med 2009;26:10031009 .

25. Hernandez D, Rose DJ. Predicting which older adults will or will not fall using the Fullerton Advanced Balance scale. Arch Phys Med Rehabil 2008:89:2309-2315 
26. Pijnappels $M$, van der Burg PJ, Reeves ND, van Dieen JH. Identification of elderly fallers by muscle strength measures. Eur J Appl Physiol 2008;102:585-592.

27. Smeesters C, Hayes WC, McMahon TA. The threshold trip duration for which recovery is no longer possible is associated with strength and reaction time. J Biomech 2001;34:589-595.

28. Bean JF, Kiely DK, LaRose S, Goldstein R, Frontera WR, Leveille SG. Are changes in leg power responsible for clinically meaningful improvements in mobility in older adults? J Am Geriatr Soc 2010;58: 2363-2368

29. Otten E. Balancing on a narrow ridge: Biomechanics and control. Philos Trans R Soc Lond B Biol Sci 1999;354:869-875.

30. Graf A, Judge JO, Ounpuu S, Thelen DG. The effect of walking speed on lower-extremity joint powers among elderly adults who exhibit low physical performance. Arch Phys Med Rehabil 2005;86:21772183.

31. Marigold DS, Patla AE. Visual information from the lower visual field is important for walking across multi-surface terrain. Exp Brain Res 2008;188:23-31.

32. England JD, Gronseth GS, Franklin G, et al. Distal symmetrical polyneuropathy: A definition for clinical research. A report of the American Academy of Neurology, the American Association of Electrodiagnostic Medicine, and the American Academy of Physical Medicine and Rehabilitation. Arch Phys Med Rehabil 2005;86:167-174.

33. Andersen H, Mogensen PH. Disordered mobility of large joints in association with neuropathy in patients with long-standing insulindependent diabetes mellitus. Diabet Med 1997;14:221-227.

34. Narici MV, Maganaris $C$, Reeves $N$. Myotendinous alterations and effects of resistive loading in old age. Scand J Med Sci Sports 2005;15: 392-401.

35. Turcot K, Allet L, Golay A, Hoffmeyer P, Armand S. Investigation of standing balance in diabetic patients with and without peripheral neuropathy using accelerometers. Clin Biomech (Bristol, Avon) 2009;24:716-721.

36. Strotmeyer ES, de Rekeneire $N$, Schwartz AV, et al. The relationship of reduced peripheral nerve function and diabetes with physical performance in older white and black adults: The Health, Aging, and Body Composition (Health ABC) study. Diabetes Care 2008;31: 1767-1772.

37. Strotmeyer ES, de Rekeneire N, Schwartz AV, et al. Sensory and motor peripheral nerve function and lower-extremity quadriceps strength: The Health, Aging and Body Composition study. J Am Geriatr Soc 2009;57:2004-2010.

38. Cammarata ML, Schnitzer TJ, Dhaher YY. Does knee osteoarthritis differentially modulate proprioceptive acuity in the frontal and sagittal planes of the knee? Arthritis Rheum 2011;63:2681-2689.

39. Woo J, Hong A, Lau E, Lynn H. A randomised controlled trial of Tai Chi and resistance exercise on bone health, muscle strength and balance in community-living elderly people. Age Ageing 2007;36:262-268.

40. Korpelainen R, Keinanen-Kiukaanniemi S, Heikkinen J, Vaananen K, Korpelainen J. Effect of exercise on extraskeletal risk factors for hip fractures in elderly women with low BMD: A population-based randomized controlled trial. J Bone Miner Res 2006;21:772-779.

41. Richardson JK, Sandman D, Vela S. A focused exercise regimen improves clinical measures of balance in patients with peripheral neuropathy. Arch Phys Med Rehabil 2001;82:205-209.

This CME activity is designated for 1.0 AMA PRA Category 1 Credit ${ }^{\mathrm{TM}}$ and can be completed online at me.aapmr.org. Log on to www.me.aapmr.org, go to Lifelong Learning (CME) and select Journal-based CME from the drop down menu. This activity is FREE to AAPMER members and $\$ 25$ for non-members.

\section{CME Question}

Improved rate of torque development in which muscle groups may enhance gait speed and efficiency in older patients with diabetic peripheral neuropathy?

a. hip abductors and ankle evertors

b. hip adductor and ankle invertors

c. hip flexors and knee extensors

d. knee flexors and ankle flexors

Answer online at me.aapmr.org 